\title{
The Dilemma of Spare Embryos After IVF Success: Social Workers' Role in Helping Clients Consider Disposition Options
}

\author{
Stephanie K. Boys \\ Julie S. Walsh
}

\begin{abstract}
Social work services for persons undergoing the in vitro fertilization process (IVF) has greatly lagged behind the medical technology opportunities provided to these clients. Advocacy for social work services for persons undergoing IVF was advanced upon the procedure's initial development, but there has been a stark lack of recent scholarship regarding social work in fertility health services. The existing literature suggests several talking points regarding the IVF process to be discussed with persons considering IVF, especially the medical and psychological risks of failure. This article discusses a newer and necessary topic to cover in pre-IVF counseling: the possibility of too much success in the form of excess embryos. Although the topic must be covered with sensitivity to the relatively low rate of IVF success, persons receiving care through assisted reproductive technology (ART) need to be prepared for the difficult moral questions raised when IVF procedures result in even more embryos than intended. Social workers need to be prepared to explore the pros and cons of each disposition option with IVF clients.
\end{abstract}

Keywords: In vitro fertilization (IVF); assisted reproductive technology (ART); reproductive counseling; frozen embryos; embryo disposition

The advance of assisted reproductive technologies (ART) has revolutionized the world of reproduction. Until approximately 50 years ago, there was one conceptual understanding of procreating: one man and one woman. Today, there are many possibilities for persons experiencing infertility, the inability to conceive due to the structure of their relationship, or the desire to be a single parent. However, along with the development of these technologies has come a vast range of ethical dilemmas. The focus of this article is a dilemma common after persons have undergone in vitro fertilization (IVF): the existence of excess embryos. Options for disposing of the embryos and considerations relevant to each option are presented.

The process of IVF involves combining egg and sperm to create embryos in a lab. In order to have the highest odds of a resulting pregnancy, as many embryos as possible are produced. Persons undergoing IVF have often experienced years of heartbreak trying to conceive naturally and view IVF as their final opportunity (Chochovski, Moss, \& Charman, 2013). Although IVF success rates have been improving, the success rate per cycle still stands at 32.7\% (Centers for Disease Control and Prevention [CDC], 2017). However, for persons who do succeed, there are often extra embryos after a live birth. The dilemma resides when parents have completed their desired family but still have fertilized embryos remaining. People are often unprepared for this situation and may be unaware of their options. Thus, many avoid the decision, leaving their embryos literally frozen in time (Nachtigall et al., 2009).

Stephanie K. Boys, PhD, JD, MSW is an Associate Professor of Social Work and Adjunct Professor of Law, Indiana University, Indianapolis, IN 46202. Julie S. Walsh, MSW, LSW is a doctoral student, School of Social Work, Indiana University, Indianapolis, IN 46202. 
The authors present a brief overview of IVF and cryopreservation, an overview of the literature on social work involvement in reproductive services, and an examination of the disposition options for spare embryos, including the pros and cons of each option.

\section{The Growth of IVF}

For most of human history, there was essentially one way to create a child that involved two persons of the opposite gender; however, the opportunities for conception have evolved rapidly since the 1970s with the development of assisted reproductive technologies (ART). One of the most dramatic advances was the invention of in vitro fertilization (IVF), a process that involves combining egg and sperm outside the human body in a petri dish prior to returning the fertilized egg into a woman's uterus.

In July 1978, the first baby produced from IVF procedures was born in England. Her parents named her Louise Brown, but she is famously known as the first "test tube baby" (Baron \& Bazzell, 2014, p. 59). The first IVF birth in the United States occurred in 1981, and today the CDC (2012) consider IVF the primary type of ART. The United States has experienced an ever-increasing number of IVF births each year, resulting in the influx of fertility clinics across the United States (Crockin \& Debele, 2014). The use of IVF doubled between 2000 and 2010, with 1\% of all infants born in the United States in 2010 as a result of IVF (CDC, 2012).

According to the CDC (2017), of the 231,936 ART cycles performed in 2015, 60,778 resulted in live births and a total of 72,913 infants; thus, approximately $1.6 \%$ of all infants born in 2015 in the United States were conceived using IVF. However, 45,779 procedures were banking cycles that resulted in eggs or embryos frozen for future use (CDC, 2017).

\section{Cryopreservation Brings about New Possibilities in IVF}

Although medical protocols vary by clinic and per individual client needs, a single IVF cycle involves several stages over a few months. First, the potential mother takes a course of medications to stimulate egg production and to prepare the uterine lining for embryo implantation. During a normal menstrual cycle, a woman produces one egg. The purpose of the IVF medications is to produce as many eggs as possible, without causing medical risks associated with hyperstimulation. Before ovulation, the eggs are retrieved in a medical procedure usually involving light anesthesia, then combined with sperm in a petri dish. The development of the embryos are monitored over the next few days since it is common for several embryos to arrest, or cease further development. On approximately the fifth day, or the blastocyst stage of development, one or more of the embryos is transferred to a woman's uterus (O'Brien, 2010). The process can vary depending on whether a couple's own egg and sperm are used, if donor egg and/or sperm are used, or if a surrogate is used (Crockin \& Debele, 2014).

When IVF practices were first developed, medical protocol was generally to transfer all created embryos to the uterus, but as the technology improved, there was a boom of multiple births (Mastenbroek et al., 2011). The risks associated with pregnancies involving multiple fetuses compelled the American Society of Reproductive Medicine (ASRM) to establish guidelines for how many embryos to transfer based primarily on the age of the 
mother, as well as other medical factors that influence success rates (Murphy, 2013). With the goal of facilitating safe, healthy pregnancies by reducing the number of embryos transferred, clients did not want to waste other embryos developed during the cycle, especially since each cycle can cost an average of $\$ 8,000$ plus $\$ 3,000-\$ 5,000$ for the necessary medications (Johnston \& Gusmano, 2013). Thus, cryopreservation technology was developed. Embryos that are well-developed but not selected for fresh transfer can be frozen, or cryopreserved (Mastenbroek et al., 2011).

The first theory of cryopreservation emerged in the 1930s by B. J. Luyet; the attempts to develop the theory into a procedure had very little success (Gosden, 2011). Over the next 40-50 years, slow progress was made by adjusting protocol, until cryo development surged almost simultaneous to in vitro fertilization. A slow freezing practice was developed in 1985 and used widely until vitrification recently became the protocol encouraged for use by clinics due to higher pregnancy rates after this faster type of freezing technology was used with embryos (Kuwayama, 2007; Whittingham, Leibo, \& Mazur, 1972). Today, over 600,000 embryos are being cryopreserved, with a 30-50\% infant birth success rate from frozen embryos (Robertson, 2014; US DHHS, 2017).

\section{Current Pre-IVF Legal Procedures}

One of the first steps in the current IVF procedure is to read and sign a large packet of informed consent documents. These documents are written by attorneys to relieve clinics of any legal liabilities; however, they are often presented to IVF clients with little explanation (Madeira, 2015). This packet includes an embryos' disposition form, which provides options regarding the status of an embryo in several circumstances including divorce, death of one of the embryo creators, and failure to pay annual storage fees.

In 2015, Madeira conducted the first, and to date only, qualitative analysis of IVF clients' perceptions and understanding of informed consent documents. The researcher interviewed 66 clients who had undergone IVF procedures. Results indicated that most of the forms are generally read and understood, except for the embryo disposition section of IVF informed consent packets. The form regarding embryo disposition shocked clients when they read it. Many participants said they felt very uninformed about the decision. They reported doing their own Internet research on IVF prior to the procedure, but said they had not thought about the possibility of embryo disposition as they were "thinking about whether or not [they could] even make an embryo" (Madeira, 2015, p. 21).

Nachtigall et al. (2009) conducted a qualitative assessment of how persons make decisions regarding how to dispose of embryos. The researchers interviewed 77 families with cryopreserved embryos and found that nearly two-thirds (63\%) of participants had embryos that had been in storage for at least five years, "either passively through disagreement or indecision or actively to maintain embryo potential, avert feelings of loss, or as psychological or genetic 'insurance'” (p. 2094). The researchers concluded that persons struggle with embryo disposition decisions after successful IVF treatment, have not considered the potential dilemma in-depth prior to undergoing IVF, and maintain cryopreservation indefinitely as a result of the struggle (Nachtigall et al., 2009). For these 
persons, excess embryos were an unintended consequence of IVF, and a dilemma they had not anticipated facing.

\section{Embryos Frozen in Time}

In the United States, approximately 600,000 embryos are currently stored in cryopreservation banks (Crockin \& Debele, 2014). This number is destined to continue rising as more persons undergo IVF and more embryos are abandoned or stored indefinitely (Tucker, 2014). Current estimates are that up to $25 \%$ of embryos in cryopreservation are abandoned as the "parents stop paying the storage fee, they move away, or they divorce and forget about their frozen embryos" (O’Brien, 2010, p. 172). The owners of the embryos might purposefully forgo paying the storage fee out of financial necessity or as a passive form of indecision about what to do with the embryos. Another reason for abandonment of embryos may be that the owners move and forget to forward their address; thus, the annual bill reflecting the need to maintain storage would be lost. In other cases, persons divorce and forget about paying or they are unable to arrive at a mutual decision. In each of these scenarios, embryos that could form life for the parents, for other persons experiencing the devastation of infertility, or that could be used to further scientific discovery are abandoned, all while taking up valuable cryopreservation space. Additionally, the ethical dilemma might continue to plague persons who knowingly abandon the embryos or later remember they were abandoned (O’Brien, 2010). While facilities may follow the legal paperwork decision of persons who abandon their embryos - be that to destroy or donate them - many facilities are loath to do so in fear that these persons might resurface, and present legal studies finding that informed consent at the time of IVF may not represent a person's decision once a child is produced and other life events have unfolded (O'Brien, 2010).

In one study, after an average of 4.2 years of cryopreservation, $72 \%$ of participants had not made a disposition decision (Nachtigall et al., 2009). In another, $87 \%$ of the participants were undecided about the disposition of leftover embryos (Clark, 2014). "Most couples had not anticipated or appreciated the consequences of having surplus embryos" (Nachtigall, Becker, Friese, Butler, \& McDougall, 2005, p. 431). Additionally, "many professionals think couples severely underestimate the difficulty of destroying remaining frozen embryos once they have a child from that batch of embryos” (Mundy, 2008, p. 185). Mundy (2008) reasons that when disposition forms are signed prior to the IVF process, embryos are merely understood to be human tissue; however, once a child has been born, the parent's understanding of the embryos transforms into a "potential child, a potential sibling, and a potential life” (p. 185).

\section{Social Work Has Not Kept Pace With Reproductive Technology}

As the use of IVF grew in the 1980s and 1990s, literature on social work services needed by persons undergoing the IVF process emerged (Blyth, 1999; Greenfeld, Mazure, Haseltine \& DeCherney, 1985; Walther, 1991). The scholarship that arose alongside the birth of IVF included discussion of the role of social workers in IVF services, the psychological and medical risks to be discussed with clients, and the counseling services necessary upon the failure of fertility treatments (Bergart, 2000; Black, Walther, Chute \& 
Greenfeld, 1992; Blyth, 1999; Daniels, 1990; Greenfeld et al., 1985; Walther, 1991). While this literature is still useful, it has failed to keep up-to-date with new technological advances such as cryopreservation and the ensuing issue of spare embryos. As IVF has become more common practice since the beginning of the new millennium, there has been a stark lack of new research on the role social workers should play in infertility health care.

Just a few years after the first baby conceived via IVF in the United States was born, Greenfeld et al. (1985) highlighted the need for specialized counseling by social workers practicing in infertility clinics. The authors presented the unique "emotional spectrum of euphoria, anxiety and dysphoria" of patients undergoing IVF, in comparison to the less invasive and less complex infertility treatments of the past (Greenfeld et al., 1985, p. 71). In addition to literature regarding social work's role during IVF procedures are studies on the services needed after unsuccessful IVF (Bergart, 2000; Black et al., 1992). Bergart (2000) argues that social workers should play a role in educating "medical professionals about the needs of their patients when treatment fails” (p. 45).

As use of IVF expanded in the 1990s, Blyth (1999) stressed the importance of social work's role at the macro level to ensure that the increasing commodification of IVF services maintained a focus on the humanity of persons experiencing infertility. The author further emphasized the need for social work advocacy on behalf of patients due to the profession's unique set of values and ethics (Blyth, 1999). More recently, Fronek and Crawshaw (2015) made a similar argument regarding the need for social workers to be advocates in international policy debates regarding bioethics matters, including IVF, among a host of other issues.

As technology has advanced, persons who undergo IVF face new challenges. Yet, the literature on social work services in the infertility field has not kept pace with technology, such as the disposition of spare embryos and the resulting ethical dilemma. The following section presents options for persons with excess embryos and how social workers can help explain those options to prospective parents.

\section{Disposition Options for Frozen Embryos}

Options for spare embryos include having more children than initially desired, undergoing compassionate transfer, donating the embryos to research, donating the embryos to prospective parents, or purposefully thawing, abandoning or indefinitely freezing the embryos. The following section provides an overview of each option. The authors do not advocate asking clients to select one of these options prior to IVF treatment since "most patients have tunnel vision focused entirely upon having a child and cannot fully appreciate the inherent complexities of decisions such as donation of excess embryos to others for procreation” (Tucker, 2014, p. 20). However, making clients aware of the possible dilemma and presenting options in advance could reduce the delay in decisionmaking later or ameliorate the abandonment of embryos in the future. Social workers need to be prepared to explore the pros and cons of each option with IVF clients. 


\section{Option 1: Have More Children}

Many people begin to contemplate the number of children they desire at a very young age, and it is often a topic of discussion for couples early in a relationship. For some, attempts to have this set number of children is stalled and marked by profound sadness and frustration. As these persons seek medical intervention to build their families, the concept of too many children is often far from their minds. The issue must be approached with the utmost consideration of the fact that some will leave IVF treatment empty-handed. However, in order to fully inform clients of the risks of IVF and prepare them for the possibility of spare embryos, the options for extra embryos must be discussed.

The most obvious solution to the spare embryo dilemma is to have more children than originally anticipated. People undergoing IVF may believe they will have as many children as are produced by the process. However, with advancing technology, the number of embryos can be quite high. The average number of eggs retrieved from a woman undergoing IVF can range from 10 to 40 (Lyon, 1999). Although it is rare for all of these eggs to reach the developmental stage necessary for transfer to a uterus or cryopreservation, it is possible that several embryos will develop. In presenting this possibility, the realities of having more children than anticipated must be presented. Because there are health issues associated with high frequency pregnancies, a higher number of embryos could be transferred at a time to reduce the number of IVF cycles and pregnancies. However, transferring more embryos heightens the risk of pregnancy with multiple babies which is risky for both the mother and the children. Cost is also an important point to consider. Well beyond the cost of multiple IVF transfers and pregnancies, families will spend an average of $\$ 233,610$ to raise a child from birth through age 17 (Lino, Kuczynski, Rodriguez, \& Schap, 2017). Finally, time is a valuable and finite resource. Potential parents must consider the time necessary to devote to each child in a large family.

\section{Option 2: Pursue Compassionate Transfer}

As an alternative to having more children for clients desiring a natural disposition of their remaining embryo(s), a new practice has been offered by some clinics termed compassionate transfer. In this process, the embryo(s) are thawed and transferred to the woman's vagina or uterus in a way that will not allow further development. If transferred to the uterus, the procedure is done without the use of hormones typically given during the IVF process to increase odds of pregnancy and during a time of the menstrual cycle that is not conducive to implantation of embryos.

Ellison and Karpin (2011), who have written one of the few scholarly pieces on compassionate transfer, contend that the practice can be presented to clients as a way to grieve the loss of the embryo as it is returned to and absorbed by the body in the same manner that is common in early-stage miscarriages. However, when presenting the option to clients during the initial IVF information stage, the cost should also be disclosed since this adds to the overall expense for IVF procedures. 


\section{Option 3: Donate to Research}

Another option for disposition of excess embryos is to donate them to research. The legality of stem cell research has changed with each recent presidential administration. If stem cell donation is not a possibility during a given time or if clients are uncomfortable with stem cell research, embryos can alternatively be donated for IVF training purposes.

Stem cell research donation. There are multiple ways embryos can be donated to research. One of the most beneficial from a practical standpoint, but also most controversial, is stem cell research. Federal regulations and funding of stem cell research has been in turmoil since its development. The William Clinton administration supported stem cell research, but was followed by the George W. Bush administration that suspended funding (Davis, 2014). The Barack Obama administration reversed that executive order (Carbone \& Cahn, 2009). It remains unclear to date what the current administration's position on stem cell research will be. Among Nachtigall and colleagues' (2009) 77 families, $22 \%$ donated their embryos to research. Clients who select this option cited four reasons: a) awareness through media publicity of the benefits of stem cell research, b) positive experiences with clinic embryologists, c) belief that their low-quality embryos are unlikely to result in conception, and d) a reconceptualization of the embryos as tissue that could be socially beneficial (Nachtigall et al., 2009).

Choosing to donate an embryo to stem cell research is dependent on donors' moral perspective on the issue. Some donors have emotionally detached from the embryo as a personal creation, and instead place value on its social benefit and contribution as an altruistic gesture (Nachtigall et al., 2009). Sympathetic donors feel that it furthers scientific understanding of diseases such as Parkinson's and diabetes, can help cure diseases, and can help further scientific infertility treatments (Kalb, 2010; Synesiou, 2010). Donors typically do not know in advance how their embryos will be used in stem cell research, so their provision of informed consent covers only the general disposition of embryos to stem cell research.

Donation for training purposes. Due to the ethical dilemmas raised by stem cell research and the legal barriers to donation for stem cell research in some states, IVF participants can choose to donate their embryos to their storing clinic for general research purposes. These embryos are often used to train lab workers on new techniques, such as removing cells for preimplantation diagnosis (PGD). This alternative may be presented to each client after discussing the pros and cons of stem cell research.

\section{Option 4: Donate to Prospective Parents}

Another option for disposing of spare embryos is to donate them to persons wishing to build their own families. Similar to the adoption process, the client could put the embryos up for adoption. Laws on this process vary by state; however, many allow donors to set the parameters of the adoption, such as whether it is open or closed and who takes possession of the embryos. In one study, only $6 \%$ of participants favored donation to other parents, with primary concerns centered around the donation process, the potential caregivers, and fear of the financial and legal ramifications (Nachtigall et al., 2009). However, these fears are mostly unfounded because organizations exist to guide people through embryo 
donation, and the cost is typically borne by the adoptive parents. Nachtigall et al. (2009) suggest making information about the organizations more widely available at IVF clinics.

In the United States, there are approximately 200,000 families seeking to adopt (Clark, 2014). Embryo adoption could substantially add to the pool of potential babies available for adoption. Persons who wish to adopt embryos desire the fullness of giving life to a child, not unlike the donor parents, which includes pregnancy, bonding, and breastfeeding (Clark, 2014); however, cost can be a substantial barrier to accessing IVF. Embryo adoption offers a less costly option. In 2014, the cost of embryo adoption averaged $\$ 5,000$ for all assessment, laboratory, and medical expenses, which is substantially less expensive than a full IVF cycle or acquisition of a donor egg (Clark, 2014).

Some embryo donors choose an open adoption program where they have the opportunity to meet with the adoptive family prior to embryo transfer and throughout the process, depending on the agreements made beforehand. According to Frith, Blyth, and Lui (2017), donors and adoptees expressed great value in having contact with each other. Both the adoptive parents and the embryo donors believed that the openness and honesty of these visits was in the best interest of the children. Alternatively, donors may opt for a closed adoption process and sign consent to do so. Regardless, discussing these options with clients up front could alleviate some of their fears and more properly address their concerns. Furthermore, counseling should be made available to families considering embryo donation (Crawshaw, Hunt, Monach, \& Pike, 2013).

\section{Option 5: Thaw, Abandon, or Indefinitely Freeze the Embryos}

The final options for persons with spare embryos after IVF treatment are to purposefully thaw the embryos, abandon them, or indefinitely cryopreserve the embryos (O'Brien, 2010). Abandonment and indefinite storage are the types of decisions that might be avoided if clients are counseled prior to undergoing IVF. Thawing the embryos involves a conscious decision to inform the clinic storing the embryos to thaw them (O'Brien, 2010). After embryos are thawed, the embryos will not develop any further and will be disposed of as biomedical waste.

Clinics typically charge an annual cryopreservation fee, which currently averages approximately $\$ 500$ a year at cryobanks (Tucker, 2014), but can be as high as $\$ 1200$ per year (Johnston \& Gusmano, 2013). Persons might fail to pay these bills for a variety of reasons including the inability to afford the bill, relocation without a forwarding address, or consciously choosing to ignore the bill in order to allow the clinic to take custody of the embryos. Clinics have the right to thaw and dispose of abandoned embryos, and many do. However, some clinics in the United States are choosing to store the embryos indefinitely due to reservations about the owners resurfacing, for moral reasons, or because of mere indecisiveness about what to do with them (O’Brien, 2010). Similarly, many people are uncertain about what to do with the embryos and continue to pay the storage fee year after year. With advances in cryopreservation protocol, embryos can remain viable indefinitely. 


\section{Importance of Social Workers Presenting the Five Disposition Options}

Pursuing IVF is an exciting, though nerve-wracking and somewhat arduous process that requires decision-making about both implanted embryos as well as those potentially left over after the completion of a family. This moral dilemma is addressed far too infrequently. Cryopreservation facilities are reaching maximum capacity and are often left in a lurch to make decisions on behalf of clients who are indecisive, do not communicate their wishes, or abandon their embryos by failing to pay storage fees. Conversely, persons beginning the IVF process experience cognitive dissonance when presented with bureaucratic forms to create life, while simultaneously being required to make what often feels like pre-mature decisions about the disposition of embryos not yet in existence and that they are fighting so hard to create. Bureaucratic demands to make decisions regarding embryo disposal prior to embryo creation results in clients feeling shocked, confused, and overwhelmed.

Social work consultation and counseling about the options available to IVF clients before they are issued consent forms might lower client anxiety. Discussing the options with a social worker requires clients to assume personal responsibility, prompts crucial discussions, and promotes ethical decision-making that is right for the family. Offering detailed information about the choices available to clients takes the mystery out of the various options. These discussions can help clients gain closure about how their remaining embryos will be handled. Ongoing social work support throughout the IVF process, as well as at the completion of family-making, would also benefit clients who may experience a shift in their moral conceptualization of embryos.

\section{Conclusion}

Success in IVF treatment is often celebrated. The moral and ethical weight of too much success, however, is often felt as a burden. Yet, the facilitation of meaningful discussion by a social worker who understands the implications of each of the options for embryo disposition helps clients to confront these dilemmas, thereby increasing their intellectual and philosophical understanding, hopefully resulting in client empowerment to make fully informed decisions.

\section{References}

Baron, N., \& Bazzell, J. (2014). Assisted reproductive technologies. The Georgetown Journal of Gender and the Law, 15, 57-93.

Bergart, A. M. (2000). The experience of women in unsuccessful infertility treatment: What do patients need when medical intervention fails? Social Work in Health Care, 30(4), 45-69. doi: https://doi.org/10.1300/J010v30n04_04

Black, R. B., Walther, V. N., Chute, D., \& Greenfeld, D. A. (1992). When in vitro fertilization fails: A prospective view. Social Work in Health Care, 17(3), 1-19. doi: https://doi.org/10.1300/J010v17n03_01

Blyth, E. (1999). The social work role in assisted conception. British Journal of Social Work, 29(5), 727-740. doi: https://doi.org/10.1093/bjsw/29.5.727 
Carbone, J., \& Cahn, N. (2009). Embryo fundamentalism. William \& Mary Bill of Rights Journal, 18, 1015-1052.

Centers for Disease Control and Prevention [CDC]. (2012). Assisted reproductive technology: National summary report 2010. Retrieved from https://www.cdc.gov/art/pdf/2010-report/ART 2010 National Summary Report.pdf

CDC. (2017). ART success rates: Preliminary data, 2015. Retrieved from https://www.cdc.gov/art/artdata/index.html

Chochovski, J., Moss, S. A., \& Charman, D. P. (2013). Recovery after unsuccessful in vitro fertilization: The complex role of resilience and marital relationships. Journal of Psychosomatic Obstetrics \& Gynecology, 34(3), 122-128. doi: https://doi.org/10.3109/0167482X.2013.829034

Clark, P. A. (2014). Ethical implications of embryo adoption, pluripotent stem cell biology. In C. Atwood (Ed.), Advances in mechanisms, methods and models (pp. 213-229). doi: http://dx.doi.org/10.5772/58592 [Available from https://www.intechopen.com/books/pluripotent-stem-cell-biology-advances-inmechanisms-methods-and-models/ethical-implications-of-embryo-adoption]

Crawshaw, M., Hunt, J., Monach, J., \& Pike, S. (2013). British Infertility Counselling Association: Guidelines for good practice in infertility counselling, 2012. Human Fertility, 16(1), 73-88. doi: https://doi.org/10.3109/14647273.2013.774217

Crockin, S. L., \& Debele, G. A. (2014). Ethical issues in assisted reproduction: A primer for family law attorneys. Journal of the American Academy of Matrimonial Lawyers, 27, 289-357.

Daniels, K. R. (1990). Psychosocial factors for couples awaiting in vitro fertilization. Social Work in Health Care, 14(2), 81-98. doi: https://doi.org/10.1300/J010v14n02_07

Davis, M. (2014). Maryland embryo adoption: Religious entanglement in the Maryland Stem Cell Research Act of 2006. University of Pennsylvania Journal of Law \& Social Change, 17, 291-327.

Ellison, D. A., \& Karpin, I. (2011). Death without life: Grievability and IVF. South Atlantic Quarterly, 110(4), 795-811. doi: https://doi.org/10.1215/00382876-1382258

Frith, L., Blyth, E., \& Lui, S. (2017). Family building using embryo adoption: Relationships and contact arrangements between provider and recipient families-A mixed-methods study. Human Reproduction, 32(5), 1092-1099. doi: https://doi.org/10.1093/humrep/dex048

Fronek, P., \& Crawshaw, M. (2015). The "new family” as an emerging norm: A commentary on the position of social work in assisted reproduction. British Journal of Social Work, 45, 737-746. doi: https://doi.org/10.1093/bjsw/bct198 
Gosden, R. (2011). Cryopreservation: A cold look at technology for fertility preservation. Fertility \& Sterility, 96(2), 246-268. doi: https://doi.org/10.1016/j.fertnstert.2011.06.029

Greenfeld, D., Mazure, C., Haseltine, F., \& DeCherney, A. (1985). The role of the social worker in the in-vitro fertilization program. Social Work in Health Care, 10(2), 7179. doi: https://doi.org/10.1300/J010v10n02_06

Johnston, J., \& Gusamano, M. K. (2013). Why we should all pay for fertility treatment: An argument from ethics and policy. Hastings Center Report, 43(2), 18-21. doi: https://doi.org/10.1002/hast.155

Lino, M., Kuczynski, K., Rodriguez, N., \& Schap, T. (2017). Expenditures on children by families, 2015. Miscellaneous Publication No. 1528-2015. Washington, D.C.: U.S. Department of Agriculture, Center for Nutrition Policy and Promotion.

Lyon, K. W. (1999). Babies on ice: The legal status of frozen embryos involved in custody disputes during divorce. Whittier Law Review, 21, 695-735.

Kalb, C. (2010, Jan. 19). All that remains: Couples who decide not to implant embryos often face a difficult choice and limited options. Newsweek. Retrieved from http://www.newsweek.com/what-happens-leftover-embryos-70777

Kuwayama, M. (2007). Highly efficient vitrification for cryopreservation of human oocytes and embryos: The cryotop method. Theriogenology, 67, 73-80. doi: https://doi.org/10.1016/j.theriogenology.2006.09.014

Madeira, J. L. (2015). The ART of informed consent: Assessing patient perceptions, behaviors, and lived experience of IVF and embryo disposition informed consent processes. Family Law Quarterly, 49(1), 7-28.

Mastenbroek, S., Van der Veen, F., Aflatoonian, A., Shapiro, B., Bossuyt, P., \& Repping, S. (2011). Embryo selection in IVF. Human Reproduction, 26(5), 964-966. doi: https://doi.org/10.1093/humrep/der050

Mundy, L. (2008). Everything conceivable: How assisted reproduction is changing our world. New York, NY: Anchor.

Murphy, J. B. (2013). Access to in vitro fertilization deserves increased regulation in the United States. Journal of Sex \& Marital Therapy, 39(2), 85-92. doi: https://doi.org/10.1080/0092623X.2011.632072

Nachtigall, R. D., Becker, G., Friese, C., Butler, A., \& McDougall, K. (2005). Parents’ conceptualization of their frozen embryos complicates the disposition decision. Fertility and Sterility, 84(2), 431-434. doi: https://doi.org/10.1016/j.fertnstert.2005.01.134

Nachtigall, R. D., MacDougall, K., Harrington, J., Duff, J., Lee, M., \& Becker, G. (2009). How couples who have undergone in vitro fertilization decide what to do with surplus frozen embryos. Fertility and Sterility, 92(6), 2094-2096. doi: https://doi.org/10.1016/j.fertnstert.2009.06.027 
O'Brien, M. (2010). An intersection of ethics and law: The frozen embryo dilemma and the chilling choice between life and death. Whittier Law Review, 32, 171-196.

Robertson, J. A. (2014). Egg freezing and egg banking: Empowerment and alienation in assisted reproduction. Journal of Law and the Biosciences, 1(2), 113-136. doi: https://doi.org/10.1093/jlb/lsu002

Synesiou, K. (2010). The dilemma of remaining frozen embryos. Retrieved from http://www.creatingfamilies.com/surrogacy/?the-dilemma-of-remaining-frozenembryos-169

Tucker, C. (2014). Abandoned embryos: The dilemma of eternal storage. New Hampshire Bar Journal, Spring/Summer, 54(3), 18-23.

U.S. Department of Health and Human Services, Office of Population Affairs [US DHHS]. (2017). Embryo adoption. Retrieved from https://www.hhs.gov/opa/aboutopa-and-initiatives/embryo-adoption/index.html

Walther, V. N. (1991). Emerging roles of social work in perinatal services. Social Work in Health Care, 15(2), 35-48. doi: https://doi.org/10.1300/J010v15n02_04

Whittingham, D. G., Leibo, S., \& Mazur, P. (1972). Survival of mouse embryos frozen to 196 degrees C. and 269 degrees C. Science, 178(4059), 411-414. doi: https://doi.org/10.1126/science.178.4059.411

Author note: Address correspondence to: Stephanie Boys, PhD, JD, MSW, School of Social Work, Indiana University, 902 W. New York St., Indianapolis, IN 46202. Email: sboys@indiana.edu 